Volume 8. No. 7, July 2020

International Journal of Emerging Trends in Engineering Research

Available Online at http://www.warse.org/IJETER/static/pdf/file/ijeter43872020.pdf

https://doi.org/10.30534/ijeter/2020/43872020

\title{
Development and Performance Evaluation of a Portable Perlite Expander Machine for Small-Scale Industries
}

\author{
Saul J. Ebonite ${ }^{1}$, Harold Jan R. Terano ${ }^{2}$ \\ ${ }^{1}$ Camarines Sur Polytechnic Colleges, Philippines, tsembuilders_ebonite@ yahoo.com.ph \\ ${ }^{2}$ Camarines Sur Polytechnic Colleges, Philippines, haroldterano@cspc.edu.ph
}

\begin{abstract}
Perlite is abundant in the Municipality of Baao, Camarines Sur, Philippines. Production of perlite are costly for small-scale industries. Common perlite expander machines are costly and large enough to produce tons of perlite, which is impossible for small-scale industries to purchase. With these, the researchers had proposed a study on the development and evaluation on the performance of a portable perlite expander machine. Using the descriptive-developmental method of research, the researchers had developed the proposed machine by applying various phases which include designing, fabrication and evaluation. The developed machine was based on its design and expected functionality. The researchers had developed the machine through various processes. The major parts of the machines are the hopper, cyclone collector, furnace and the input to burner. The burner used is a torch burner operating at a temperature ranging from $700^{\circ}$ to $1,000^{\circ} \mathrm{C}$. Based on the testing, the developed machine operates at a capacity of 250 grams in 1 hour and expands raw perlite to an average of 17 times its original volume. The idea of the development of this machine is to further improve the livelihood of the constituents of Baao, Camarines Sur, Philippines. By introducing them a technology that will enable them to produce perlite at low cost, this study was realized.
\end{abstract}

Key words : Expander machine, perlite, portable perlite, portable perlite expander machine

\section{INTRODUCTION}

Heat treatment and applications of heat is one of the main methods in improving properties of materials [1,2]. With heat applications, the needed properties and qualities of materials based on its applications can easily be achieved. Perlite is a substance that has many commercial and industrial uses. Also known as volcanic glass, perlite is used in agriculture, shipping, medicine and a host of other applications [3]. Perlite expands by a factor of 4-20 when rapidly heated to $1400-1800^{\circ} \mathrm{F}\left(760-980^{\circ} \mathrm{C}\right)$ [4]. Due to its low bulk density is used mainly in building materials technology as a filler in lightweight composites, thermal, acoustic, fire insulation as well as in horticulture and agriculture [5]. Many industrial applications for perlite have developed in construction and manufacturing fields. Perlite especially expanded perlite is used in fillers, construction, filters, lightweight plasters, concrete and mortar (masonry), insulation and ceiling tiles [6].

Various studies proved that perlite powder has many applications. It has been used as the replacement of cement. Perlite addition improved the durability of concrete to a large extent [7]. Lightweight concrete was developed by admixing with perlite; replacement of sand with 30, 40 and 50\% of perlite produces lightweight concrete and 50\% sand replacement with perlite gives the lowest density [8].

An extensive study on the structural, physical and mechanical characteristics was done. The proposed material obtained fall into the category of lightweight concrete, in terms of density, thermal conductivity and strength. Due to the characteristics determined on the research, the materials can be used in construction for increasing thermal resistance of the envelope as finishing materials [9].

A study on the characteristics and applications of perlite showed that there are various applications of perlite. Such applications include insulation in masonry construction. For insulating low temperature and cryogenic vessels, perlite is an ideal solution. When perlite is used as an aggregate in concrete, a lightweight, fire resistant, insulating concrete is produced that is ideal for roof decks and other applications. Perlite can also be used as an aggregate in Portland cement and gypsum plasters for exterior applications and for the fire protection of beams and columns. Other construction applications include under-floor insulation, chimney linings, paint texturing, gypsum boards, ceiling tiles, and roof insulation boards [10].

Investigation of expanded perlite showed that it can be used as a construction raw material. The characteristic properties, as well as its physical properties at different temperatures (up to $600^{\circ} \mathrm{C}$ ) were investigated. The perlites, having glassy, porous structure, were found to contain $70.68 \% \mathrm{SiO}_{2}$ and $13.04 \%$ $\mathrm{Al}_{2} \mathrm{O}_{3}$. The physical properties of perlite changes with temperature [11]. 
Perlite is naturally abundant in the Philippines, like in the Bicol region specifically in the Municipality of Baao, Camarines Sur, Philippines. The researchers came up with the idea of developing a machine that can be used for perlite production. Current perlite expander machines are for use for large-scale applications which turn to be expensive to be owned by ordinary constituents.

With this, the researchers had decided to design and develop a perlite expander machine that is portable, which is less expensive compared to the existing machines. By this, constituents of the said locality can have the opportunity to own perlite expander machine at a lesser cost but of the same efficiency with the existing machines in the market. The developed machine has the function to expand perlites, thus can be a useful benefit not only to those who need perlites, but can be utilized by the community for livelihood production.

This study was focused on the development and evaluation of a portable perlite expander machine for small-scale industries. Specifically, it sought to address the following objectives; (1) to design a portable machine that expands perlite; (2) to fabricate the machine; and (3) to evaluate the performance of the machine in terms of capacity and expanded volume.

\section{MATERIALS AND METHODS}

The study is a descriptive-developmental research. The research process involves various phases which includes designing, fabrication and evaluation. The development process is shown in figure 1.

Designing phase consists of the planning and analysis to develop the design of the machine. Planning involves various activities which consists of interview with the constituents of Municipality of Baao, Camarines Sur, Philippines on the need of a machine that will be capable of expanding perlites which is abundant in their locality. The researchers plan and analyze the possible design of a perlite expander machine based on the interview gathered from the constituents, the availability of the raw materials to be used, and its specific functions.

The fabrication phase consists of the construction, testing and modification of the machine based on its designed features and functionality. The construction of the machine was based on its design. After machine was constructed, testing was followed. Testing was done to ensure that all the parts of the machine were functional based on its design. Modifications of some parts were done in every testing made.

The evaluation phase is the final phase which tests the performance of the machine in terms of the capacity and the expanded volume.

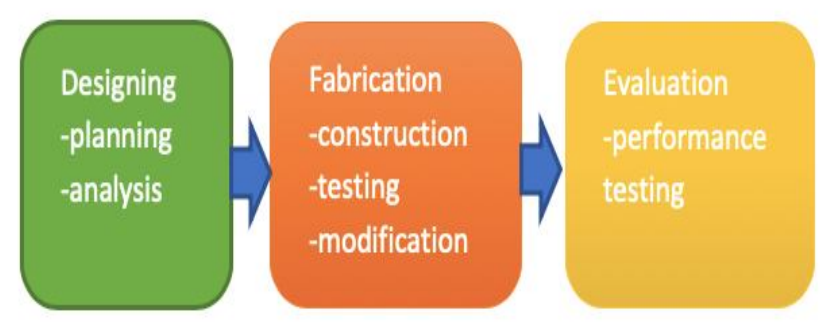

Figure 1: Development Process

\section{RESULTS AND DISCUSSIONS}

This section discusses the results of the study based on its objectives.

\subsection{Design of the Machine}

The design of the machine is shown in figure 2. The main parts of the machine compose of hopper, cyclone collector, furnace and the input to burner. The hopper is the storage container that is being used to dispense the perlite. It is in a shape of inverted pyramid to restrict the flow of the perlite. It measures about $20.4 \mathrm{~cm}$ in width and $50.5 \mathrm{~cm}$ in height.

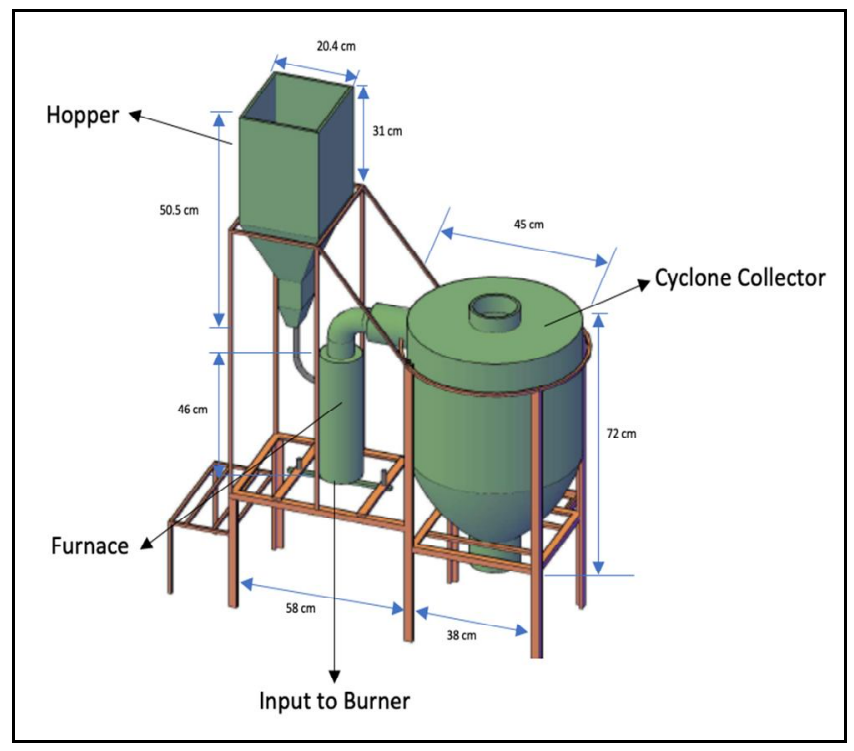

Figure 2: Design of the Machine

The cyclone collector is the part of the machine that is used to circulate the expanded perlites. These denser particles strike the wall of the collector and then fall to the bottom. It has an outlet at the top where the air will flow out. The cyclone collector is in cylindrical form at the top which has a diameter of $45 \mathrm{~cm}$, and conical below. The height of the cyclone collector is $72 \mathrm{~cm}$. 
The furnace is the part of the machine used for high temperature heating. It is where the burner is placed fueled by liquified petroleum gas. It has a height of $46 \mathrm{~cm}$ and radius of $10 \mathrm{~cm}$. The burner is designed to operate at a temperature ranging from $700^{\circ} \mathrm{C}$ to $1,000^{\circ} \mathrm{C}$. The machine is designed for a capacity of 250 grams of perlite per operation.

\subsection{Development of the Machine}

The machine was developed based on its design and expected functionality. The researchers had developed the machine through various processes. These include cutting of metal and steel bars, welding, grinding and installing of parts. Actual developed machine is shown in figure 3.

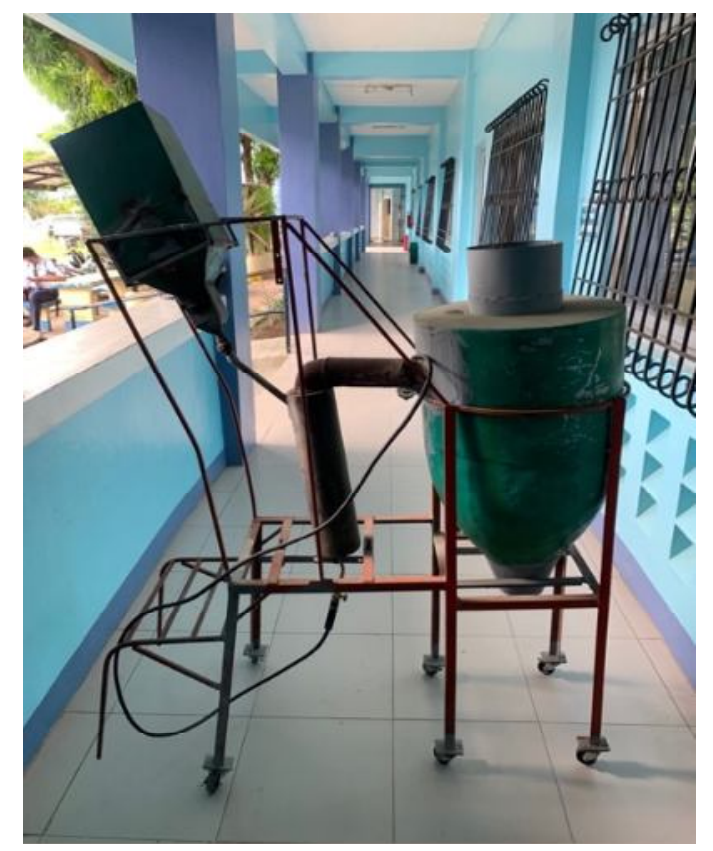

Figure 3: Developed Machine

During the testing for the functionality, various modifications on the design were considered. The hopper had been modified to maximize the dispensing of the perlite. It was tilted to about $45^{0}$ so that the perlite will be dispensed efficiently. Rollers were put at the legs of the machine for easier movements from one place to another.

\subsection{Performance Evaluation}

The machine underwent several trials to determine its performance in terms of the output capacity as a function of time duration and expanded volume. Table 1 shows the result of the testing to determine the output (in grams) per time (in minutes).
In trial 1, the output capacity is 248 grams, while trials 2 and 3 are both 250 grams. Trials 4 and 5 are both 252 grams.

Based on the results, it is found that the machine operates an average of 250.40 grams in 1 hour.

Table 1: Capacity

\begin{tabular}{|c|c|c|c|c|c|c|}
\hline \multirow[b]{2}{*}{$\begin{array}{l}\text { Time } \\
\text { (min.) }\end{array}$} & \multicolumn{5}{|c|}{ Output Capacity (grams) } & \multirow{2}{*}{$\begin{array}{l}\text { Averag } \\
\quad \text { e }\end{array}$} \\
\hline & $\begin{array}{c}\text { Tria } \\
11\end{array}$ & $\begin{array}{c}\text { Tria } \\
12\end{array}$ & $\begin{array}{c}\text { Tria } \\
13\end{array}$ & $\begin{array}{c}\text { Tria } \\
14\end{array}$ & $\begin{array}{c}\text { Tria } \\
15\end{array}$ & \\
\hline 10 & 24 & 25 & 23 & 24 & 24 & 24.00 \\
\hline 15 & 45 & 43 & 45 & 44 & 44 & 44.20 \\
\hline 20 & 68 & 65 & 66 & 64 & 66 & 65.80 \\
\hline 25 & 90 & 92 & 90 & 88 & 89 & 89.80 \\
\hline 30 & 110 & 113 & 110 & 112 & 108 & 110.60 \\
\hline 35 & 134 & 132 & 132 & 130 & 132 & 132.00 \\
\hline 40 & 150 & 152 & 149 & 148 & 148 & 149.40 \\
\hline 45 & 175 & 174 & 175 & 174 & 175 & 174.60 \\
\hline 50 & 196 & 200 & 198 & 198 & 200 & 198.40 \\
\hline 55 & 225 & 233 & 228 & 230 & 232 & 229.60 \\
\hline 60 & 248 & 250 & 250 & 252 & 252 & 250.40 \\
\hline
\end{tabular}

Figure 4 shows the graphical representation of the output amount per unit time based on the data gathered in table 1 .

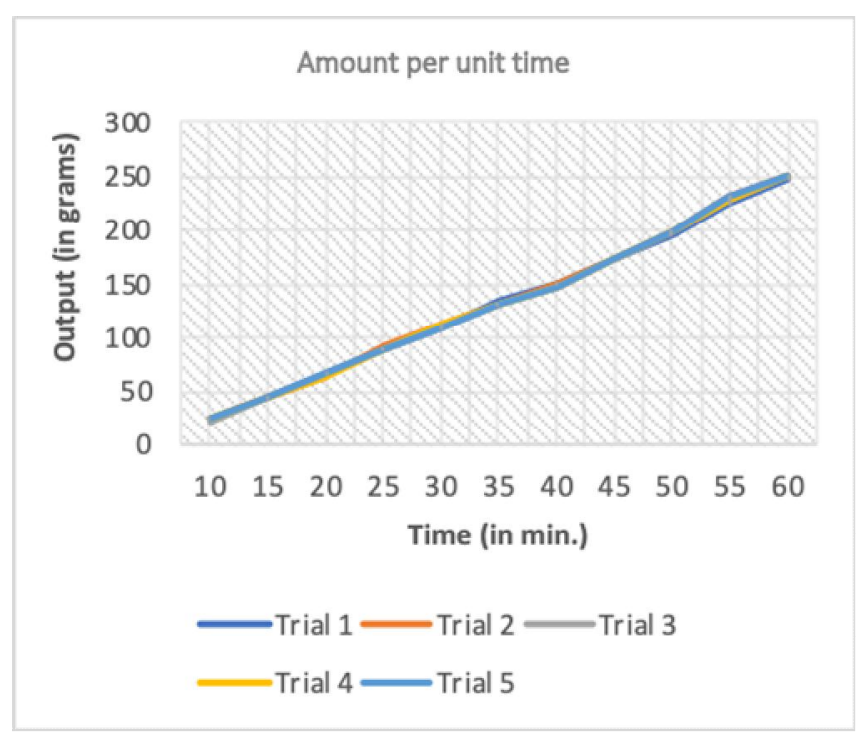

Figure 4: Graphical Representation of the Output Amount per unit Time

Table 2 shows the expanded volume for the various trials. The input volume is based on the amount of mass for the set trials. The density of unexpanded (raw) perlite is $1.1 \mathrm{~g} / \mathrm{m}^{3}$, which means that the volume of a 250 grams perlite is around 227.27 $\mathrm{cm}^{3}$. 
Saul J. Ebonite et al., International Journal of Emerging Trends in Engineering Research, 8(7), July 2020, 3140 - 3144

Table 2: Expanded Volume

\begin{tabular}{c|c|c}
\hline \hline \multirow{2}{*}{ Trial No. } & \multicolumn{2}{|c}{ Output } \\
\cline { 2 - 3 } & Expanded volume $\left.\mathbf{( c m}^{\mathbf{3}}\right)$ & Increase Times \\
\hline 1 & 3,800 & 16.72 \\
\hline 2 & 4,050 & 17.82 \\
\hline 3 & 3,950 & 17.38 \\
\hline 4 & 4,000 & 17.60 \\
\hline 5 & 3,900 & 17.16 \\
\hline Average & $\mathbf{3 , 9 4 0}$ & $\mathbf{1 7 . 3 4}$ \\
\hline \hline
\end{tabular}

Trial 1 has an expanded volume of $3,800 \mathrm{~cm}^{3}$ (16.72 times).

Trial 2 is $4,050 \mathrm{~cm}^{3}$ (17.82 times). Trial 3 is $3,950 \mathrm{~cm}^{3}(17.38$ times). Trial 4 is $4,000 \mathrm{~cm}^{3}$ (17.60 times). And trial 5 is 3,900 $\mathrm{cm}^{3}$ (17.16 times). Based on the results of the testing, it is found that the average expanded volume for a 250-gram perlite is $3,940 \mathrm{~cm}^{3}$. The average increase is about 17.34 times. It is supported by the study of Maxim, et al. (2014) that perlite expands by a factor of 4-20.

\subsection{Monitoring}

Figures 5 and 6 show the monitoring of the Philippine Council for Industry, Energy and Emerging Technology Research and Development as the funding agency of the research.

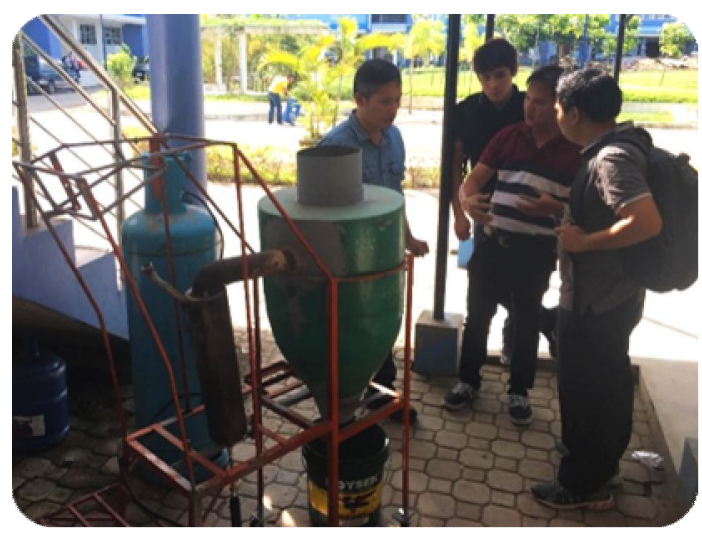

Figure 5: Monitoring

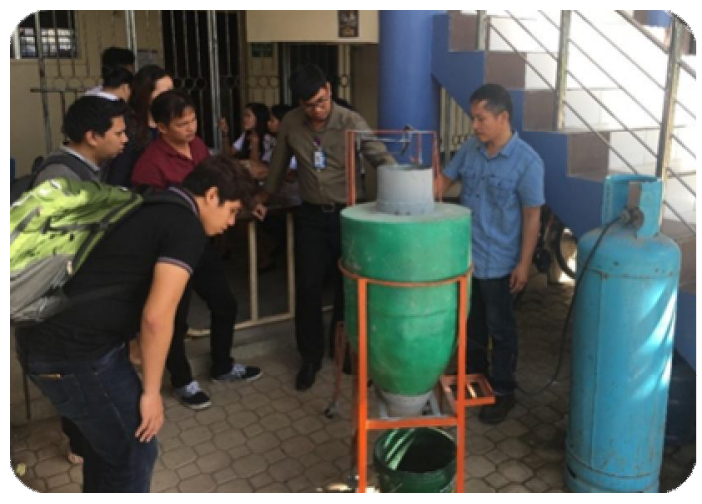

Figure 6: Monitoring

\section{CONCLUSION AND RECOMMENDATIONS}

The portable perlite expander machine was developed to expands raw perlite to up to an average of 17 times its original volume. The machine is effective in expanding the perlites where the burner used operates at $700^{\circ} \mathrm{C}$ to $1,000^{\circ} \mathrm{C}$. It was designed for small-scale industries in the Municipality of Baao, Camarines Sur, Philippines where perlites are abundant.

Further improvement on the design can be done for high capacity operation and decrease the time of operation. Increasing the size of the furnace in the design may help improve the operation time. Various sizes of output perlites can be considered by designing different mesh sizes. Electronic automation on the operation can be included for future development of this present machine. The developed machine is now ready for pilot testing and be adopted by the target beneficiaries specifically the constituents in the Municipality of Baao, Camarines Sur, Philippines.

\section{ACKNOWLEDGEMENT}

This research was funded in collaboration with the Philippine Council for Industry, Energy, and Emerging Technology Research and Development (PCIEERD) and Camarines Sur Polytechnic Colleges (CSPC), Philippines. The authors would like to thank the Camarines Sur Polytechnic Colleges (CSPC), the PCIEERD, and other people who are in one way help the researchers finished this study.

\section{REFERENCES}

1. Smirnova, Z.V., Vaganova, O.I., Kutepova, L.I., Kuttepov, M.M. and Chaykina, Zh.V. Steel heat treatment technology. International Journal of Emerging Trends in Engineering Research, Vol.8, No. 5, pp. 1790-1793, 2020. https://doi.org/10.30534/ijeter/2020/49852020

2. Estacio, A.G., Pagtalunan, V.C., Pagtalunan, R.S., Valenzuela, I.C., Tolentino, L.S., and Dela Cruz, J.C. characterization of high temperature calibration bath through stability and uniformity tests with data acquisition using standard platinum resistance thermometer and precision multimeter. International Journal of Emerging Trends in Engineering Research, Vol.7, No. 10, pp. 388-392, 2019. https://doi.org/10.30534/ijeter/2019/047102019

3. Velardo, M.D. (2017). What is perlite? Retrieved from https://sciencing.com/perlite-5402928.html.

4. Maxim, L. D., Niebo, R. and McConnell, E. E. Perlite toxicology and epidemiology - a review. International Forum for Respiratory Research, Vol. 
26, No. 5, pp. 259-270, 2014. Retrieved at https://www.tandfonline.com/doi/full/10.3109/089583 78.2014.881940.

https://doi.org/10.3109/08958378.2014.881940

5. Raji, M., Nekhlaoui, S., El Hassani, I., Essassi, E. M., Essabir, H., Rodrigue, D., Bouhfid, and R., Qaiss, A. Utilization of volcanic amorphous aluminosilicate rocks (perlite) as alternative materials in lightweight composites. Composites Part B: Engineering, Vol. 165, pp. 47-54. 2019. Retrieved from

https://www.sciencedirect.com/science/article/pii/S13 59836818322558?via\%3Dihub.

6. Bolen, W. P. Perlite USGS 2009 Minerals Yearbook, US, 2009.

7. . Khanna, P., Mukulam, A. M., Teja, K. V., and Meena, T. Study on durability properties of perlite incorporated concrete. International Journal of Civil Engineering and Technology, Vol. 9, No. 10, pp. 1545-1553, 2018.

8. Sriwattanapong, M., Sinsiri, T., Pantawee, S., and Chindaprasirt, P. A study of lightweight concrete admixed with perlite. Suranaree Journal of Science and Technology, Vol. 20, No. 3, pp. 227-234, 2013.

9. Pruteanu, M., Diaconu, L. I., Rujanu, M. and Babor, D. Studies on the possibilities of using expanded perlite for reducing buildings energy consumption. Environmental Engineering and Management Journal, Vol. 15, No.5, pp. 1103-1108, 2016. https://doi.org/10.30638/eemj.2016.123

10.Samar, M. and Saxena, S. Study of chemical and physical properties of perlite and its application in India. International Journal of Science Technology and Management, Vol. 5, No. 4, pp. 70-80, 2016.

11. Celi, A. G., Kilic, A. M. and Cakal, G. O. Expanded perlite aggregate characterization for use as a lightweight construction raw material. Physicochemical Problems of Mineral Processing, Vol. 49, No. 2, pp. 689-700, 2013. 